\title{
Evaluate E-loyalty of sales website: a Fuzzy mathematics method
}

\author{
Ying $\mathrm{Yi}^{1}{ }^{1}$ Zhen-yu Liu ${ }^{2}$, Ying-zi Xiong ${ }^{3}$ \\ 1 School of Management, Xiamen University, Xiamen,361005,P.R.China \\ yidiandian99@sina.com \\ 2 School of Management, Xiamen University,Xiamen,361005,P.R.China \\ freiman@sina.com \\ 3 School of Management, Xiamen University,Xiamen,361005,P.R.China \\ xyingzi@xmu.edu.cn
}

\begin{abstract}
The study about online consumer loyalty is limited, but how to evaluate the customers' E-loyalty to a sales website is always a noticeable question. By using some methods of fuzzy mathematics, we provide a more accurate way to evaluate E-loyalty of sales website. Moreover, this method can differentiate level and degree of each factor that influences E-loyalty.
\end{abstract}

\section{Introduction}

With the development of electronic commerce, more and more companies have conducted online sales in their website. Generally, customers' switching costs of sales website is very low. For customer, jumping from one website to other alternative websites that offer similar products or services is very easy, just a click of mouse. Therefore a company must take some measures to retain their online customers. First of all, a company needs to know the customers' E-loyalty to their sales website. By evaluating the website E-loyalty degree, a company can find defects, then take action to improve customers' E-loyalty.

In this paper, website E-loyalty means online customers' loyalty to sales website. We know that costs associated with acquiring new customers is five times the costs of retaining customers[1]. In electronic commerce, research has revealed that keeping and attracting customers is so expensive and switching online is so easy[2]. This is why E-loyalty is so important to retailer online. Loyal customers would often visit your website and purchase merchandise. Loyal customers want to be associated with your website, and tell other people about your website. Loyal customers don't even want to consider the competition's offers. E-loyalty means that

Please use the following format when citing this chapter:

Yi, Y., I fu, Z,.-Y., Xiong, Y.-Z, 2007, in IFIP International Federation for Information Processing, Volume 252, Integration and Innovation Orient to L-Society Volume 2, eds. Wang, W, (Boston: Springer), pp. 582-589. 
you can get a much bigger piece of each customer's lifetime value. Consequently, your profits would increase, and your stock prices would get higher.

Anyway, retailer online should evaluate its customers' E-loyalty and try to improve it. However evaluating E-loyalty is difficult because too many factors would influence E-loyalty, and the effect of each factor is different. Existing evaluating method usually don't differentiate effect of each factor, and factors are too miscellaneous. This reduces accuracy and usability of E-loyalty evaluating result.

In this paper, we provide a more accurate way to evaluate E-loyalty of sales website. We use some methods of fuzzy mathematics to evaluate E-loyalty. Using these methods we can differentiate effect of each factor.

\section{Four-layer comprehensive evaluation index system}

Many scholars have investigated online customer's switching behaviors. Some people study the difference of online customers. They analyze online customers' behavioral patterns, attitudes, demographic characteristics, and so on. They try to find out character and discriminate factors between stayers and switchers $[3,4,5]$.

To establish evaluation index of E-loyalty, we are more interested in studies that investigate impact factors of E-loyalty. Based on conventional theory of consumer behavior, research has showed that customer loyalty and retention lie on customer satisfaction and switching barriers[6,7,8].Chen and Hitt found that customer demographic characteristics have little effect on switching online, but that systems usage measures and systems quality are associated with reduced switching[9]. Based on relationship marketing theory, commitment and trust are the main reasons for customer to stay with a business. The effects of these social and psychological factors are very important for customer retention.

Actually, the customers' E-loyalty to a sales website comes from many aspects. As we describe above, most studies show that these factors include customer satisfaction, switching barriers, commitment, trust and so on. To describe directly all these factors using quantitative index is almost impossible. However we find that these factors lie on the quality, service, action of website ultimately. So we adopt an indirect method to deal with this problem. We can describe the customers' E-loyalty to a sales website by a series of website evaluating index.

Indeed, a single index can't reflect all factors. In order to provide an effective evaluation, it is necessary to establish a systematic comprehensive index system. In order to distinguish so many factors, we should classify these factors in terms of characteristic of the factors. So we introduce a four-layer comprehensive evaluation index system by settling correlative study results.

According to existing correlative study and our analysis, we think the E-loyalty comes from customer satisfaction, switching costs and trust. Research has indicated that satisfaction have significant effect on online customer loyalty[6,8]. But customer satisfaction is a necessary condition of E-loyalty, not a sufficient condition . Online customers are likely to switch to other sales websites and select other E-retailers even though they are very satisfied with your online sales. In fact, switching costs is the actual reason preventing customer from switching. Switching costs is all expenses when customer switches to other suppliers which includes two kinds of 
costs. One can be scaled by currency while another can't be scaled by currency. In the later kind of switching costs, the most important representation is trust. So the factors effecting customers' E-loyalty are classified as three sorts, that is, customer satisfaction, switching costs and trust . Each sort needs to be subdivided. In the end, we establish a four-layer comprehensive evaluation index system.

We think E-loyalty comes from three aspects. Each aspects is influenced by many factors, we subdivide and conclude a hierarchy of primary factors(see Table 1).The analysis is chiefly based on existing study results $[5,9,10,11]$.

So the E-loyalty is determined by three combined index, i.e. $O=f\left(U_{1}, U_{2}, U_{3}\right)$. Combined index $\mathrm{U}_{1}$ is determined by combined $\mathrm{U}_{11}, \mathrm{U}_{12}, \mathrm{U}_{13}, \mathrm{U}_{14}, \mathrm{U}_{15}$, and combined index $U_{j j}$ is determined terminal index $U_{i j k}$. The index, $U_{2}$ and $U_{3}$, are similar. The value of terminal index can be given by experts and customers.

Table 1. the four-layer comprehensive evaluation index system

\begin{tabular}{|c|c|c|c|}
\hline First layer & Second layer & Third layer & Fourth layer \\
\hline \multirow{22}{*}{$\begin{array}{c}\mathrm{O}: \\
\text { E-loyalty }\end{array}$} & \multirow{18}{*}{$\begin{array}{c}\mathrm{U}_{\mathrm{I}}: \\
\text { Customer } \\
\text { satisfaction }\end{array}$} & \multirow{3}{*}{$\begin{array}{l}\mathrm{U}_{11} \text { : laying out } \\
\text { merchandise }\end{array}$} & $\mathrm{U}_{111}$ : convenient navigation \\
\hline & & & $\mathrm{U}_{112}:$ variety of merchandise \\
\hline & & & $\mathrm{U}_{\mathrm{I13}}:$ update speed \\
\hline & & \multirow{5}{*}{$\begin{array}{l}\mathrm{U}_{12}: \text { usability of } \\
\text { website }\end{array}$} & $\mathrm{U}_{121}:$ speed of download \\
\hline & & & $\mathrm{U}_{122}$ : variety information format \\
\hline & & & $\mathrm{U}_{123}:$ security \\
\hline & & & $U_{124}:$ stability \\
\hline & & & $\mathrm{U}_{125}:$ accessibility \\
\hline & & \multirow{4}{*}{$\begin{array}{l}\mathrm{U}_{13}: \text { transaction } \\
\text { process }\end{array}$} & $\mathrm{U}_{131}$ :choose and buy \\
\hline & & & $\mathrm{U}_{132}$ : deal with order \\
\hline & & & $\mathrm{U}_{133}:$ payment \\
\hline & & & $\mathrm{U}_{134}:$ delivery \\
\hline & & \multirow{3}{*}{$\begin{array}{l}\mathrm{U}_{14}: \text { support and } \\
\text { service }\end{array}$} & $\begin{array}{c}\mathrm{U}_{14 i}: \text { various service and support } \\
\text { mode }\end{array}$ \\
\hline & & & $\begin{array}{c}\mathrm{U}_{142} \text { : responding speed of service and } \\
\text { support }\end{array}$ \\
\hline & & & $\begin{array}{c}\mathrm{U}_{143}: \text { conformity of online and } \\
\text { offline }\end{array}$ \\
\hline & & \multirow{3}{*}{$\begin{array}{l}\mathrm{U}_{15}: \text { provision of } \\
\text { information and } \\
\text { tool }\end{array}$} & $U_{151}:$ search engine \\
\hline & & & $\mathrm{U}_{152}:$ other helpful information \\
\hline & & & $\begin{array}{c}\mathrm{U}_{153}: \text { tools of analysis and } \\
\text { comparison }\end{array}$ \\
\hline & \multirow{4}{*}{$\begin{array}{c}U_{2}: \\
\text { Switching } \\
\text { costs }\end{array}$} & \multirow{2}{*}{$\begin{aligned} \mathrm{U}_{21}: & \text { renege on the } \\
& \text { contract }\end{aligned}$} & $\mathrm{U}_{2 \mathrm{H}}:$ renege compensation \\
\hline & & & $\mathrm{U}_{212}:$ bargaining costs \\
\hline & & $\begin{array}{c}\mathrm{U}_{22}: \text { repetitive } \\
\text { purchase discount }\end{array}$ & \\
\hline & & $\begin{array}{l}\mathrm{U}_{23}: \text { profit from } \\
\text { loyal plan }\end{array}$ & \\
\hline
\end{tabular}




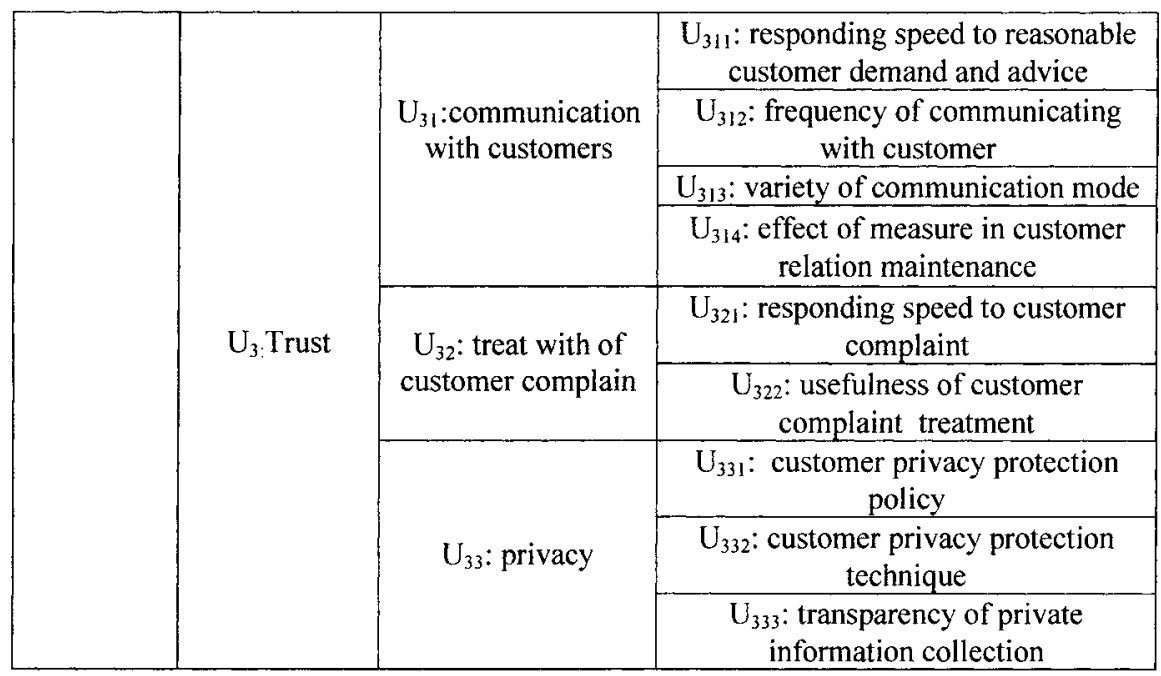

\section{Fuzzy comprehensive evaluation model}

Comprehensive evaluation includes three elements: evaluation index, evaluation value and evaluation result. For each evaluation index, we can acquire a evaluation value, and this evaluation value forms a evaluation result. In fuzzy comprehensive evaluation [12], evaluation index is a set of index, and evaluation value is a set of remarks. For example, the evaluation value is $\mathrm{V}=$ \{very satisfied, satisfied , appreciably satisfied, not satisfied $\}$. Assuming evaluation index as set $U=\left\{u_{1}, u_{2}, \ldots u_{n}\right\}$, evaluation value as set $\mathrm{V}=\left\{\mathrm{v}_{1}, \mathrm{v}_{2}, \ldots \mathrm{v}_{\mathrm{m}}\right\}$, the evaluation result is a fuzzy mapping:

$$
\text { f : } U \rightarrow F(V)
$$

the fuzzy mapping $\mathrm{f}$ forms a fuzzy relation $\mathrm{R}, \mathrm{R}$ is a matrix:

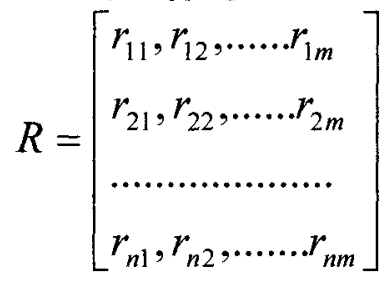

Because weightiness of each evaluation index is different, we should distribute each evaluation index a weighting coefficient. Assuming the weighting coefficient set as

$$
A=\left(a_{1}, a_{2}, \ldots . . a_{n}\right)
$$

Then fuzzy comprehensive evaluation is calculated as follows:

$$
B=\left(b_{1}, b_{2}, \ldots . . b_{m}\right)=A \circ R
$$




$$
b_{i}=\sum_{j}\left(a_{j} \times r_{j i}\right)
$$

in Eq.(4), we use "+" and " $x$ " operators instead of Zadeh operators(max and min)in order to get a normalization result.

Our evaluation index system has four-layer, so the comprehensive evaluation is calculated as follows:

$$
\begin{aligned}
& O=A \circ B=A \circ\left[\begin{array}{l}
B_{1} \\
B_{2} \\
B_{3}
\end{array}\right]=A \circ\left[\begin{array}{l}
A_{1} \circ C_{1} \\
A_{2} \circ C_{2} \\
A_{3} \circ C_{3}
\end{array}\right] \\
& C_{1}=\left[\begin{array}{l}
C_{11} \\
C_{12} \\
C_{13} \\
C_{14} \\
C_{15}
\end{array}\right]=\left[\begin{array}{l}
A_{11} \circ R_{11} \\
A_{12} \circ R_{12} \\
A_{13} \circ R_{13} \\
A_{14} \circ R_{14} \\
A_{15} \circ R_{15}
\end{array}\right] \\
& C_{2}=\left[\begin{array}{l}
C_{21} \\
R_{22} \\
R_{23}
\end{array}\right]=\left[\begin{array}{l}
A_{21} \circ R_{21} \\
R_{22} \circ R_{22} \\
R_{23} \circ R_{23}
\end{array}\right] \\
& C_{3}=\left[\begin{array}{l}
C_{31} \\
C_{32} \\
C_{33}
\end{array}\right]=\left[\begin{array}{l}
A_{31} \circ R_{31} \\
A_{32} \circ R_{32} \\
A_{33} \circ R_{33}
\end{array}\right]
\end{aligned}
$$

where vector $A$ denotes the weighting coefficients of second layer index $U_{1}, U_{2}, U_{3}$. Similarly, vector $A_{1}, A_{2}, A_{3}$ and $A_{i j}$ are the weighting coefficients of third layer index and fourth layer index.

$$
\begin{aligned}
& A=\left(a_{1}, a_{2}, a_{3}\right) \\
& A_{1}=\left(a_{11}, a_{12}, a_{13}, a_{14}, a_{15}\right) \\
& A_{11}=\left(a_{111}, a_{112}, a_{113}\right) \\
& A_{12}=\left(a_{121}, a_{122}, a_{123}, a_{124}, a_{125}\right) \\
& A_{13}=\left(a_{131}, a_{132}, a_{133}, a_{134}\right) \\
& A_{14}=\left(a_{141}, a_{142}, a_{143}\right) \\
& A_{15}=\left(a_{151}, a_{152}, a_{153}\right)
\end{aligned}
$$




$$
\begin{aligned}
& A_{2}=\left(a_{21}, a_{22}, a_{23}\right) \\
& A_{21}=\left(a_{211}, a_{212}\right) \\
& A_{3}=\left(a_{31}, a_{32}, a_{33}\right) \\
& A_{31}=\left(a_{311}, a_{312}, a_{313}, a_{314}\right) \\
& A_{32}=\left(a_{321}, a_{322}\right) \\
& A_{33}=\left(a_{331}, a_{332}, a_{333}\right)
\end{aligned}
$$

Matrix $R_{i j}$ is evaluation result, determined by fuzzy mapping:

$$
\mathrm{f}_{\mathrm{ij}}: U_{\mathrm{ij}}>\mathrm{F}(\mathrm{V})
$$

Rij can be obtained from experts' grade or/and customers inquiry. The process of obtaining these data is very simple. A company merely needs to send questionnaire to experts and customers through Internet, and call back questionnaire. In ecommerce circumstance, it is easy and low-cost. Certainly, the company should use right manner and means so that customers are willing to accept survey. In this way, the company could achieve high ratio of questionnaire callback. The evaluation result based on enough data is effective .

\section{Determining weighting coefficients of the comprehensive evaluation model}

There are many factors that influence E-loyalty. We differentiate these factors by classification, and establish fourth-layer index system. The effect of each index is different, so each index is distributed a weighting coefficient. But how to determine weighting coefficients is more accurate? There are many methods that we can choose to determine weighting coefficients. These methods are the Delphi method, the comparative matrix method, the analytical hierarchy process (AHP) and so on. When we implement fuzzy comprehensive evaluation, we can select an appropriate method according to convenience of data collection and decision environment. If the weighting coefficients can be directly determined, we can choose the Delphi method. If the data can be compared in pairs, we can choose the comparative matrix method. If the relative importance of index can be estimated, we can choose AHP.

Usually, weighting coefficients should conform to consistency, so we should make consistency test. If weighting coefficients can't conform to consistency, we should determine weighting coefficients once again. In the end, we should make weighting coefficients normalization to obtain final weighting coefficients.

The process of determining weighting coefficients is indicated in Fig.1. 


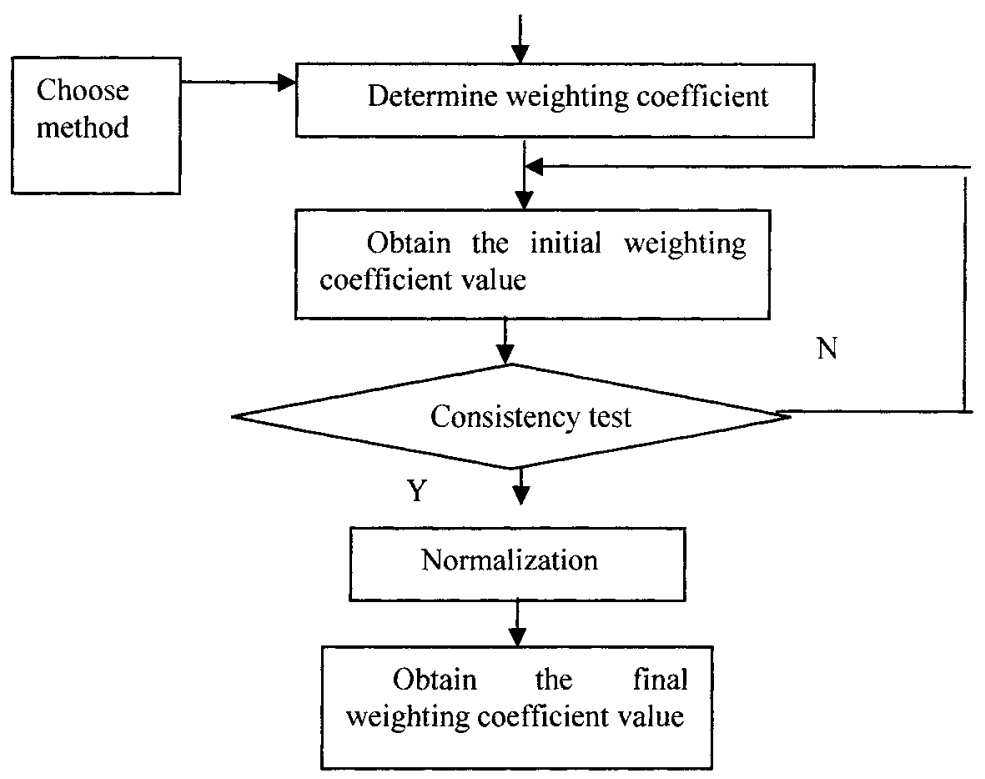

Fig. 1. the process of determining weighting coefficients

\section{Conclusion}

In this paper, we propose a four-layer evaluation index system and a fuzzy comprehensive evaluation model for evaluating E-loyalty of sales website. The main advantage of this method is that those factors affecting E-loyalty of sales website can be classified by four layers, and different effect of each factor can be differentiated by weighting coefficient. Moreover, the evaluation process, including data collection and calculation, is simple and feasible.

This model can be implemented conveniently on microcomputer using computer programming language and a relational database. For a sales website, evaluating its E-loyalty frequently, discovering existing disadvantage and improving E-loyalty is very important in fierce market competition.

\section{References}

1. S.M. Keaveney, "Customer switching behavior in service industries: An exploratory study", Journal of Marketing, 59,71-82 (1995). 
2. F.F. Reichheld and P. Schefter, "E-loyalty: Your secret weapon on the Web", Havard Business Review, 78(4),105-113(2000).

3. S.M. Keaveney and M. Parthasarathy, "Customers switching behavior in online services: An exploratory study of the role of selected attitudinal, behavioral , and demographic factors", Journal of the Academy of Marketing Science,29(4), 374-390(2001).

4. D. Gefen , E. Karahanna , and D. Straub, "Trust and TAM in online shopping: An integrated model", MIS Quarterly,27(1), 51-90(2003).

5. D.H .Li, G.J. Browne, and J.C. Wetherbe, "Online consumers' Switching behavior: A Buyer-Seller Relationship Perspective", Journal of Electronic Commerce in Organizations,5(1), 30-42(2007).

6. A. Bhattacherjee, "Understanding information systems continuance: An expectation confirmation model", MIS Quarterly,25(3), 351-370(2001).

7. C. Flavian, M. Guinaliu, and R. Gurrea, "The role played by perceived usability, satisfaction and consumer trust on Website loyalty", Information \& Management,43(1), 1 14(2006).

8. C. Park and Y. Kim, "The effect of information satisfaction and relational benefit on consumers' online shopping site commitments", Journal of Electronic Commerce in Organizations, 4(1), 70-90(2006).

9. P.Y. Chen and L.M. Hitt, "Measuring Switching costs and Their Determinants in InternetEnabled Businesses: A Study of the Online Brokerage Industry", Information System Research, 13(3),255-274(2002).

$10 . N$. Sharma and P. Patterson, "Switching costs, alternative attractiveness and experience as moderators of relational commitment in professional consumer services", International Journal of Service Industry Management, 11(5),470-482(2000).

11.J.E. Collier and C.C. Bienstock, "How Do Customers Judge Quailty in a Etailer?" MITSloan Management Review,48(1),35-40(2006).

12.L.B. Yang and Y.Y. Gao, Fuzzy mathematics: theory and application(South China University of Technology Press, Guangzhou,2001). 